\title{
A QUESTÃO TEMPORAL EM O DESERTO DOS TÁRTAROS, DE DINO BUZZATI
}

\section{THE TEMPORAL ISSUE IN THE TARTAR STEPPE, BY DINO BUZZATI}

\section{EL PROBLEMA TEMPORAL EN EL DESIERTO DE LOS TARTAROS, POR DINO BUZZATI}

\author{
Eduardo de Lima Beserra ${ }^{1}$ \\ Nefatalin Gonçalves Neto ${ }^{2}$
}

1. Graduando em Letras pela Universidade Federal Rural de Pernambuco, Unidade Acadêmica de Serra Talhada (UFRPE/UAST). Bolsista do Programa de Educação Tutorial (PET/CS - Comunidades Populares) e integrante do Grupo de Pesquisa em Literatura, Estudos Culturais e Socioambientais. Contato: eduardolima9705@gmail.com

2. Pós-Doutorando em Literatura Portuguesa pela Faculdade de Filosofia, Letras e Ciências Humanas da Universidade de São Paulo (FFLCH/USP) e professor da Universidade Federal Rural de Pernambuco, Unidade Acadêmica de Serra Talhada (UFRPE/UAST). Contato: nefa.usp@ gmail.com

RESUMO: Este trabalho apresenta um estudo do romance $O$ deserto dos Tártaros, de Dino Buzzati, no qual procuramos investigar a passagem do tempo na obra, dando ênfase às anacronias de antecipação, ou prolepses. Ao observar esse fenômeno, abordamos a categoria narrativa de tempo em termos objetivos e subjetivos. $\mathrm{Na}$ análise, as prolepses estão adjacentes em função da progressão do enredo e sob as condições dos aspectos da temporalidade. Ao centrar a discussão acerca do tempo narrativo, o trabalho sustenta-se nos estudos teóricos de Genette (1978), Candido (1996) e Nunes (2013). De modo introdutório, apresentaremos alguns dados do romance, bem como o resumo da obra em apreço.

Palavras-chave: $O$ deserto dos Tártaros. Tempo. Prolepses. Objetividade. Subjetividade.

\begin{abstract}
This essay presents a study on the novel The Tartar steppe by Dino Buzzati in which it was aim at to dig into time passing through the literary work emphasizing anachronism of anticipation, or prolepses. As this phenomenon is observed it broaches the narrative category of time in objectively and subjectively terms. In the analyses, the prolepses are adjacent to the storyline progression and under conditions of the aspects of temporality. Focusing the discussion on narrative time, the work lies in the theoretical studies of Genette (1978), Candido (1996) and Nunes (2013). In an introductory way, it is presented some novel data as well as the abstract of the work literary in hand.
\end{abstract}

Keywords: The Tartar steppe. Time. Prolepses. Objectivity. Subjectivity.
RESUMEN: Este trabajo presenta un estudio de la novela El desierto de los Tártaros, de Dino Buzzati, en la que intentamos indagar en el paso del tiempo en la obra, enfatizando anacronías de anticipación o prolepsos. Al observar este fenómeno, nos acercamos a la categoría narrativa del tiempo en términos objetivos y subjetivos. En el análisis, los prolepsos son adyacentes según la progresión de la trama y bajo las condiciones de los aspectos de temporalidad. Al centrar la discusión en el tiempo narrativo, el trabajo se basa en los estudios teóricos de Genette (1978), Candido (1990) y Nunes (2013). De forma introductoria, presentaremos algunos datos de la novela, así como el resumen del trabajo en cuestión.

Palabras-clave: El desierto de los Tártaros. Tiempo, Prolepses. Objectividad. Subjectividad.

Recebido em: 25/08/2020

Aprovado em: 05/10/2020

Todo o conteúdo deste periódico está licenciado com uma licença Creative Commons (CC BY-NC-ND 4.0 Internacional), exceto onde está indicado o contrário. 


\section{Introdução}

Refletir acerca do tempo, decerto, é uma tarefa hercúlea. Ao longo dos séculos, muitos estudiosos debruçaram-se ao tema a fim de compreender as dinâmicas desse fenômeno que se desdobra sobre a humanidade de diversas formas. O tempo físico, embora pareça palpável porque toma a objetividade da realidade para se firmar, esvai-se quando se tenta apurar seu âmago. O tempo psicológico, que parece não obedecer a qualquer coisa, não demora, curva-se perante as sutilezas da linguagem e do experimentalismo humano. Em todo caso, é areia movediça, e seu refletir gera mais problemas que resoluções.

Para além de tais reflexões, parece-nos que há um outro tipo de tempo o qual, em alguma medida, iguala-se ao psicológico, mas que é tempo interior, inefável, intransferível ao verbo e aos instrumentais de análise. Tais reflexões, muitas vezes amparadas em apenas ponderações subjetivas, sem escopo físico, incomodaram séculos aos filósofos mais interessados nelas. Ao perquirirmos tais caminhos, encontramos na literatura, com suas vias de possibilidades e aberturas, é um espaço ímpar para que apliquemos tais reflexões. Partindo de tal pressuposto, temos que em $O$ deserto dos Tártaros, o tempo plasma-se nas refregas existenciais do personagem central. Isto é, os conflitos relativos ao tenente - personagem principal da trama - se dão, densamente, nas vias subjetivas de sua vida. A temporalidade se deixa ver no processo de espera que não só marca e determina sua vida, como a de todos os outros militares que estão na Fortaleza Bastiani. A expectação gera iminências angustiantes, também criadora de armadilhas arquitetadas pelo sentimento heroico que insufla as personagens. Reportar-se ao passado, bem como se inclinar à esperança e aos anseios instauram o embate existencial do romance. Pela figura do tenente, o tempo se deixa perceber como matéria de angústia e concretiza-se como o clepsidra - a fluidez vagarosa, entrecortando a vida entre a possibilidade de vislumbrar outros horizontes de sobrevivência e/ou permanecer cativo à espera.

O deserto dos Tártaros, romance do escritor italiano Dino Buzzati, veio a lume no ano de 1940. Nele, narra-se a história de Giovanni Drogo, tenente recém-formado, convocado a prestar serviços na Fortaleza Bastiani. Infundido pelas forças de seu ofício, Drogo segue viagem, guiado pelos cumes de montanhas, transpassando caminhos tortuosos e desconhecidos. $\mathrm{O}$ incomum da viagem projeta no jovem oficial algumas estranhezas, descompassos e reiterações entre projetos de vida e de destino. Contudo, lampejos de esperança lhe tomam de assalto e o fazem continuar a caminhada em busca de catalisar seus sonhos, fazendo-o comprazer-se diante dos méritos desejados. Ao chegar ao forte, Drogo toma conta de que as coisas ali não eram como imaginara. Há muitos anos batalhas não eram travadas naquele lugar; o forte se mantinha por um estado amorfo de espera, pelo roldão de que, em algum momento, os Tártaros proclamariam um combate. O conflito não era iminente, senão aquele que se instaurava no corpo e no espírito de cada militar resguardado pela Fortaleza. 
O impacto do que vê e sente vacila, veementemente, a vida de Giovanni Drogo em um ínterim temporal abismático. Tudo que fizera e por que passara para estar ali parecia não ter valido mais a pena. A impressão primeira fez-se arrasadora. Desse modo, a ânsia de reaver outros meios de sobrevivência reincidiu sobre o tenente; ele era jovem, o tempo parecia estar ao seu lado, poderia ir embora do forte, mitigar suas frustrações por via das guinadas da existência. Conquanto, ir de encontro ao sistema no qual estava inserido, num sopro de exasperação, poderia esmaecer sua carreira militar. Nesse sentido, a personagem opta por permanecer na Fortaleza por, pelo menos, quatro meses - cumprindo com serviços os quais lhe foram destinados. A condição para sua saída seria alegar, por meio de avaliação médica, que não estaria apto a continuar no forte, portanto, deveria ser remanejado para o mais próximo possível da família.

Quatro meses transcorreram, e chega o dia em que Giovanni Drogo fará o exame para a transferência. Apresenta-se ao médico, iniciando uma conversa entrecortada por divagações pouco elucidativas e carregadas de incertezas. A ambientação, elevada, com ares de púlpito, coloca o jovem tenente em um estado de sublimação — de cima, via o que o olhar ainda não havia alcançado. Diante de uma janela, Drogo fita a planície inóspita, observa os rochedos em torno da Fortaleza, examina as razões pelas quais estava ali e, como gota d'água despencando numa superfície metálica aquecida, esfacela seu anseio de deixar o lugar. Um sentimento de júbilo parece ter se apoderado dele; a condição de herói, enfim, havia se apossado dos seus sentidos e de suas ações.

Integrado, definitivamente, ao forte, Drogo passa a introjetar os hábitos e as formas de rotina sem lassidão que lá encontrara. Seu senso de espera ganha novos contornos, agora mais determinados, calcados tanto nos sobressaltos de murmúrios quanto dos desassossegos oriundos, ambos, do deserto. Na medida em que esse processo se estabelece, ele transita entre memórias, expectativas e posturas que assume em relação ao tempo, à esperança e às escolhas. As elucubrações feitas por Drogo perpetram ecos constantes em sua existência, o que faz com que a questão temporal evidencie-se, afinal, é justamente a forma como Drogo lida com o tempo e seu insucesso em "vencê-lo" que o leva a refletir sobre sua condição existencial. Há, em outros termos, uma demora da personagem em entender que o valor do tempo está na ação implicada sobre ele.

Trinta anos se passam e, então, os Tártaros atacaram a Fortaleza Bastiani. O deserto, finalmente, torna-se campo de batalha. A confiança se converte em divã da morte. Não há mais espera, mas também não há prazeres ou heroísmo, resta apenas a compleição tanto física quanto psíquica do tenente - as duas laceradas pelo tempo e pela angústia do querer. Ele não pode mais exercer o seu papel triunfante e não alcançará os méritos dirimidos pela guerra. Com isso, Drogo perde sua estadia na Fortaleza e é transferido para uma casa de repouso, onde, numa excentricidade familiar, a aridez, a opacidade e a nudez de uma parede qualquer torna-se a última paisagem de desalento na sua existência. A morte adentra seu reduto de modo silente e, com delicadeza, ceifa-lhe a vida de esperas. 


\section{Considerações sobre o tempo em $O$ deserto dos Tártaros}

Nunes (2013) traça uma diferenciação entre o tempo real e o tempo imaginário a partir da classificação tradicional da temporalidade (física e psicológica). Nessa perspectiva, “direta ou indiretamente, a experiência individual, externa e interna, bem como a experiência social ou cultural, interfere[m] na concepção do tempo" (NUNES, 2013, p. 18).

$\mathrm{O}$ autor aponta que o tempo físico tem uma relação de causa e efeito, exprime o movimento exterior das coisas, pode ser medido, gera processos de modificações (perceptíveis) e tem caráter pragmático. Dessa forma, "a objetividade do tempo físico se apoia no princípio de causalidade [...] na conexão entre causa e efeito, como forma de sucessão regular dos eventos naturais. [...] O efeito não pode se dá antes da causa" (NUNES, 2013, p. 19). Por conseguinte, o filósofo paraense apresenta a irreversibilidade do tempo objetivo (real) cujo processo tem um direcionamento e está associado ao tempo livre, esse, estritamente relativo às experiências humanas. "Mas a sua direção, que lhe empresta o atributo da finitude, segue, de momento a momento, entre passado e futuro, a linha fugidia dos instantes vividos, encurtada à proporção que a vida se alonga, aproximando-nos da morte" (NUNES, 2013, p. 20).

Em outros termos, podemos afirmar que as constatações de Nunes sugerem que o tempo vivido tem ligação com os estados internos dos sujeitos e escapa às medidas temporais objetivas. Ou seja, é imensurável. A esse respeito, ele ainda assevera:

A experiência da sucessão dos nossos estados internos leva-nos ao conceito de tempo psicológico ou de tempo vivido, também chamado de duração interior. O primeiro traço do tempo psicológico é sua permanente descoincidência com as medidas temporais objetivas. Uma hora pode nos parecer tão curta quanto um minuto se a vivemos intensamente; um minuto pode parecer-nos tão longo quanto uma hora se nos entediamos. Variável de indivíduo para indivíduo, o tempo psicológico [...] é a mais imediata e mais óbvia expressão temporal humana (NUNES, 2013, p. 19, grifo do autor).

Ademais, “o tempo psicológico se compõe de momentos imprecisos, que se aproximam ou tendem a fundir-se, o passado indistinto do presente, abrangendo, ao saber de sentimentos e lembranças, intervalos heterogêneos incomparáveis" (NUNES, 2013, p. 19). Essa condição o difere do tempo físico em razão de este se sustentar no princípio de causalidade, mencionado anteriormente.

Embora haja distinções entre o tempo mensurável e o tempo que escapa ao cômputo, é possível apreender uma aproximação entre ambos, já que ter consciência do tempo físico, em determinadas ocasiões, é um fator de delineamento das sensações humanas, da sucessão dos estados internos. Acerca dessa asseveração, Santos e Oliveira (2001) afirmam: 
Costumamos pensar o tempo segundo duas perspectivas. Uma perspectiva objetiva que associa, ao tempo, aspectos cosmológicos, físicos [...] E uma outra perspectiva [...] que torna possível falar de tempo psicológico, subjetivo, ou tempo imaginário. O mais interessante é que os dois enfoques são indissociáveis: a percepção, independentemente do grau de liberdade imaginativa, só pode ocorrer a partir de um tempo que efetivamente transcorre, que deixa marcas concretas na realidade física. Já o tempo físico só adquire alguma significação [...] a partir de alguma consciência [...] que se projeta sobre ele (p. 52-53, grifo do autor).

Essa colocação dialoga com a pluralidade do tempo vista em Nunes já que este, em sua reflexão, entende a noção de tempo como conceptualmente profusa. Ou seja, ele é plural, nunca singular ou único quando além do individual. Todavia, "suas várias modalidades não são díspares, a todas se aplicam a noção de ordem, duração e direção que recobrem relações variáveis entre acontecimentos” (NUNES, 2013, p. 22).

Em As astúcias da enunciação, Fiorin (1996) reitera, com seus conceitos de tempo físico, tempo cronológico e tempo linguístico, as reflexões iniciais de Nunes. O primeiro tipo de tempo se refere ao intervalo entre o início e o fim de um movimento; o segundo, estabelece uma sucessão de acontecimentos a partir de demarcações no tempo físico e, finalmente, o tempo linguístico é aquele que possibilita a localização dos acontecimentos em função do momento da enunciação ${ }^{1}$. Para o autor, o momento da enunciação é regido por dois marcos temporais, o concomitante e o não concomitante; este projeta o pretérito e o futuro, aquele é responsável pela configuração do presente. Nesse sentido, é em função do momento da enunciação que os marcos temporais são estabelecidos, de modo explícito ou não, no texto (FIORIN, 1996, p. 143).

Por fim, podemos entender que "o que o tempo linguístico tem de singular é que está organicamente ligado ao exercício da palavra [...] Esse tempo tem seu centro no presente da instância do verbo" (BENVENISTE, 1973, p. 73, apud NUNES, 2013, p. 22). À vista do afirmado, Nunes (2013), ressalta que a enunciação é o elemento emergencial do presente e constitui o tempo próprio da linguagem. Por outro lado, pretérito e futuro fazem-se como perspectivas oscilatórias a partir do presente. Dessa forma, “o tempo linguístico, tempo do discurso, que não se reduz às divisões do tempo cronológico, revela a comunicação intersubjetiva da comunicação linguística" (NUNES, 2013, p. 22, grifo do autor).

Fiorin (1996) reclama para sua discussão acerca das categorias enunciativas o conceito de debreagem temporal, que corresponde a instalação da categoria de tempo no texto. Em consonância, Nunes (2013) acentua que o intercâmbio linguístico se atualiza no texto escrito em função das orientações espaçotemporais fornecidas pelo tempo cronológico. Assim,

\footnotetext{
${ }^{1}$ Compreendemos anunciação como o ato de dizer e o enunciado como produto da enunciação. Cf. Reuter (2004).
} 
É a partir dos personagens, dos enunciados a respeito deles ou daqueles que proferem, que fica demarcado o presente da enunciação: os dêiticos, hoje, amanhã, depois, funcionam dentro de um intercâmbio linguístico que se passa entre esses interlocutores, e sem o qual o enquadramento cronológico seria um molde abstrato. O tempo linguístico dependerá do ponto de vista da narrativa, seja da visão onisciente ou impessoal, de proximidade ou de participação [...] do narrador sobre os personagens, seja de sua visão identificada com um deles [...]. (NUNES, 2013, p. 23).

Como bem explicita Fiorin (1996), se a linguagem copiasse os tempos do mundo, as narrativas só poderiam ser feitas no pretérito. Entretanto, a narração pode ser realizada a partir de qualquer tempo, o que permite, por parte do narrador, uma manipulação do modo de contar que traveste a narrativa de significados que extrapolam o simples "dizer por dizer". O linguista expõe, ainda, que cada narrativa gera uma construção de linguagem, haja vista o tempo ser uma constituição dela. Narrar no presente, passado ou futuro é uma escolha puramente linguística. Para o autor, as narrativas do presente tanto criam um efeito de sincronia entre o narrado e a narração quanto projetam a sensação de um evento se dando no instante em que se lê algo. É como se o leitor estivesse presente nas situações narradas. Já as narrativas direcionadas ao futuro, ocorrem quando se supõe, imagina ou profetiza algum acontecimento porvindouro.

Segundo Reuter (2004), a ficção se constitui de ações, as quais são efetivadas pelas personagens em um determinado tempo e espaço. As ações também são o elemento de movimento da narrativa; ou seja, é por meio delas que a história progride e desenvolve o sentido da trama, alterando o estado dos demais constituintes da diegese. Nas palavras do pesquisador,

\begin{abstract}
De modo similar, as indicações temporais podem "ancorar" o texto no real, quando elas são precisas e correspondem às nossas divisões, ao nosso calendário ou a acontecimentos comprovadamente históricos. Alguns romances privilegiam o passado [...]; outros são centrados na atualidade ou num período recente; outros escolhem a ucronia [contos fantásticos]; outros, ainda, o futuro [...] ou o embaralhamento de nossas categorias (REUTER, 2004, p. 61).
\end{abstract}

Nesse sentido, as narrativas, em geral, não obedecem a um modelo cabal de trabalho com o tempo, haja vista ele ser uma construção de linguagem e, portanto, estar à mercê do ponto de vista de quem narra. Isso relaciona conceitos essenciais no efeito de temporalidade, a saber, o momento, a velocidade, a frequência e a ordem. Esses elementos colocam em confronto o discurso narrativo e a história (ficção).

$\mathrm{Na}$ leitura de $O$ deserto dos Tártartos, observamos certas particularidades no uso que o narrador faz do tempo. Já Antonio Candido, em seu artigo As quatro esperas, havia constatado no romance de Buzzati um jogo dividido em dois tempos, a saber, a incorporação à fortaleza - com dois tempos que funcionam como jogo: esperança e morte - e o de desincorporação - segundo momento do jogo, também de esperança e morte.

Para Candido (1990), o Forte representa uma experiência de vida, "um modo de ser e viver, que prende os que têm a mesma natureza idealista e ansiosa de Drogo; os que traduzem a própria situação como 
longa espera do momento glorioso e único, onde tudo se justifica e o tempo é redimido" (CANDIDO, 1990, p. 58). A incorporação à Fortaleza acontece sem que Drogo se dê conta, o que sugere um deslumbramento ligado aos seus anseios militares. Além disso, Drogo, gradativamente, vai se ancorando no espaço, introjetando hábitos e posturas que, a princípio, eram alvos da indiferença do jovem tenente, pois ele não desejava entrar em estado de espera, como os demais militares que habitavam a Fortaleza Bastiani. Assim, ao mesmo tempo em que nega a realidade, a personagem se choca com imagens que fazem referência ao tempo futuro e desarticulam o projeto existencial em construção da personagem. Essa falta de consonância entre vida e sonho, expressa pela não concomitância do enunciado com o momento da enunciação, traça um paralelo e um contraste "entre a morte sonhada e a morte real" (Cf. CANDIDO, 1990). Vejamos, segundo tal perspectiva, como essa falta de consonância se dá no romance.

Se tomados com certa atenção, temos em $O$ deserto dos Tártartos dois momentos impares, a saber: “[...] tenha cuidado, estou lhe dizendo, o senhor se deixará sugestionar, também o senhor acabará ficando, basta olhá-lo nos olhos.” (BUZZATI, 2017, p. 44); e “- Estou bem - repetiu Drogo, quase não reconhecendo a própria voz. - Estou bem e quero ficar” (BUZZATI, 2017, p. 55). Para além de uma nuance quase imperceptível, os dois trechos trabalham, de forma exemplar, um jogo entre objetividade e subjetividade, dado que a qualidade objetiva do enunciador se perde, nos dois momentos, pois há uma reportação para ações futuras, que não acontecem na realidade narrativa. Tais fatos, por estarem ligados à condição abstrata do personagem central, Giovanni Drogo, atingem alcance e amplitude ${ }^{2}$ importantes. O primeiro, de alcance relativamente próximo, é evocado na primeira citação e não demora muito para que ocorra, confirmandose logo na segunda. Ora, essa confirmação apresenta caráter de objetividade, pois é certo: a personagem vai ao médico da Fortaleza a fim de realizar o exame demissional, resultante do período de quatro meses que Drogo estabeleceu para ficar no Forte Bastiani, mas se deixa sugestionar pela força do sentimento heroico que o envolve em severas expectativas. Essa primeira prolepse é uma resposta, a antecipação de um acontecimento que o realça. A saída de Drogo, antecipada discursivamente, tem a finalidade de repercutir o fato tanto na narração quanto no enunciatário. Em outras palavras, o sonho é o que manterá a personagem viva. Sua efetivação o destruirá.

A projeção para além da ação no segundo excerto serve como uma completude, uma forma de a personagem acreditar naquilo que conta. Essa enunciação de um acontecimento que que seria contado na devida altura presta-se para autorizar o sujeito para si, de forma a fazer com que o leitor confie em sua narrativa e entre em crise quando constata que a personagem é transferida para um internato de repouso.

Já quanto à amplitude, concernente à velocidade dos acontecimentos e a duração da narração, e notável que o narrador habilmente pausa a narrativa para fazer com qu, por meio de rpoleses, o narratario

\footnotetext{
${ }^{2}$ Em Nunes (2013), alcance diz respeito ao período de tempo que as anacronias ocupam a partir do momento em que começa; a amplitude se refere à duração do evento que as anacronias introduzem, alcançando ou não o evento principal. 
constate a ideia de imobilidade. Como exemplo, temos: "Drogo porém não sabia, não suspeitava que a partida the daria trabalho, nem que a vida do forte engolia os dias um após o outro, todos iguais, numa velocidade [...]" (BUZZATI, 2017, p. 57) e "Quase dois anos depois, Giovanni Drogo dormia uma noite em seu quarto, no forte. Vinte e dois meses haviam passado sem trazer nada de novo, e ele permanece firme, esperando [...]” (BUZZATI, 2017, p. 61).

Nos dois fragmentos citados a amplitude não é longa. No primeiro, em tons de subjetividade, o narrador anuncia que o tempo se projetaria para Drogo como algo nocivo à sua existência. Tal questão é ratificada na segunda passagem, que aponta a ausência de fatos consideráveis para a vida de Giovanni Drogo em um período de dois anos. Nesse caso, a amplitude se dá na dimensão de cinco páginas, emolduradas pelo imaginário cíclico do personagem. O primeiro excerto, ao antecipar e retomar ao momento pré-antecipado, constrói, por seu declarado caráter prospectivo, alusões a um futuro particularmente ruim, sem charme, desconstruído, acentuando a curiosidade do leitor, antecipando um conhecimento imediato e superficial de situações, cuja condução e desfecho não são surpreendentes, mas anseiam a um projeto aparentemente moral. No segundo caso, é possível depreender que não há uma homologia entre a sucessão real dos acontecimentos da história e a ordem na qual esses acontecimentos são narrados (Cf. REUTER, 2004). O enunciador, responsável pela organização dos elementos que compõe a narrativa, determina a sucessão dos fatos em função da relação que mantém com as ações sem, no entanto, fazer-se profecia, muito menos premonição. A atmosfera criada angaria e reforça o tom moralizante afirmado anteriormente.

As prolepses são produzidas em contextos diversos, não são apenas evocadas pela voz do narrador, mas também pela voz das personagens. Essas prolepses formam grupos com características comuns associadas ao tempo, ao espaço e à condição existencial. É justamente por meio dessa problemática temporal que tanto a personagem quanto nós, leitores, nos damos conta de que o tempo essencial de que trata o romance é fluido e rapidamente se esvai. E isso fica claro no final da trama; após anos de espera, os inimigos marcham vindos do deserto prontos para ataque, Giovani Drogo, porém, muito doente e debilitado é forçado a retornar para casa e, no caminho, decide pernoitar numa hospedaria. É neste local, uma hospedaria estrangeira, onde Drogo enfrenta seu destino e, logo na sequência, quando se interna, recebe a morte, compreendendo, então, que jamais realizaria seus sonhos e que jamais teria como justificar sua espera ou ser recompensado pelo seu esforço - a oportunidade de morrer gloriosamente, apesar de só, em um campo de batalha em terra estrangeira, contra um inimigo nunca antes enfrentado não existe, o que resta é apenas o tempo em extinção. 


\section{Articuladores da objetividade e da subjetividade}

O romance todo se passa para que vejamos que é o tempo quem governa a vida de Drogo. As prolepses presentes no romance são, em sua grande maioria, enunciadas pelo narrador para permitir que existam duas visões distintas sobre a vida da personagem: a visão dela mesma sobre si (quase uma exotopia) e a visão do enunciatário sobre esse sujeito inacabado, em busca de sua própria construção.

Esses fatos, que demandam a significação mais ampla do romance, podem ser melhor observados nos fragmentos: “[...] Aquele era o primeiro laço, e depois viriam muitos outros, de toda espécie, que o trancariam lá dentro.” (BUZZATI, 2017, p. 12); “[...] oh, se o soubesse, talvez não tivesse vontade de dormir -, justamente aquela noite iria começar para ele a irreparável fuga do tempo.” (BUZZATI, 2017, p. 38) e "Drogo porém não sabia, não suspeitava que a partida lhe daria trabalho, nem que a vida do forte engolia os dias um após o outro, [...] numa velocidade vertiginosa” (BUZZATI, 2017, p. 57).

Nos fragmentos citados, o narrador enuncia acontecimentos em linhas de subjetividade a partir de contextos distintos. No primeiro, Drogo está deixando a cidade em direção ao Forte Bastianni, momento em que também se despede do seu amigo de infância Francesco Vescovi. Tais fatos, mais íntimos, acabam por criar um clima de angústia e saudosismo, e a consciência do narrador se manifesta com o intento de difundir a permanência desse afeto na personagem. Mas, para além dessa permanência, a reflexão deque o passado carrega lembranças jamais re-experienciáveis marca, tanto na personagem quanto no enunciatário, a frugalidade da vida, bem como suas fraquezas. Já no segundo trecho, a personagem, imergida no sono, em estado de distensão da vida, apresenta, em uma mistura de vozes com a do narrador, a maleabilidade de sua existência. Em um solilóquio um tanto quanto inusitado, Drogo dialoga com uma consciência que o intriga, uma vez que age enquanto a personagem está em estado de inércia. Destarte, temos explicitado, por meio do processo composicional de reflexão, o inacabamento da personagem e sua vontade, mesmo insustentável, em alcançar seus anseios e delineamento sócio psicológicos.

Por fim, o terceiro fragmento salienta um futuro ameaçador, que expõe o personagem ao declínio/degradação de sua própria vida. A morte como que bate à porta. O processo de mudança implica em novo gasto de vida, a reflexão sobre o passado sugere que as normas estabelecidas no forte, mesmo deixadas para trás, ainda imperam em relação à vida do indivíduo. Quando tenta se desincorporar da Fortaleza, Drogo apenas se dá conta de sua condição de frustração: não existe verdadeiro desvencilhamento do passado; o não-dito das entrelinhas da narrativa estabelece um jogo de vida determinante que se faz presente para determinar a vida e seu fim.

Voltando novamente aos entrechos do romance, podemos constatar que as prolepses que partem do protagonista refletem incertezas, questionamentos e aconselhamentos vãos, embora não muito explícitos. Os contextos se dão em torno de um único espaço, o forte, como denunciam as passagens: “[...] Tenha 
cuidado, estou lhe dizendo, o senhor se deixará sugestionar, também o senhor acabará ficando, basta olhálo nos olhos.” (BUZZATI, 2017, p. 44); “[...] Um por um, vão-se todos - murmurava Rovina na penumbra. - Acabaremos por ficar apenas nós, os velhos. Este ano...” (BUZZATI, 2017, p. 54) e “[...] acreditamos que ao redor haja criaturas semelhantes a nós e, ao contrário, só há gelo, pedras que falam uma língua estrangeira; preparamo-nos para cumprimentar o amigo, mas o braço recai inerte, o sorriso se apaga, porque percebemos que estamos completamente sós” (BUZZATI, 2017, p. 60).

A primeira passagem se dá na oficina do alfaiate Prosdocimo. A prolepse parte de um personagem identificado apenas como "Velhinho", que conversa das coisas fatais e invisíveis que afetam a todos no forte - sugerindo a Drogo o desprendimento imediato do lugar mesmo tendo em vista que, de alguma forma, o aconselhamento se tornaria em vão. Já o segundo fragmento se dá nas instâncias da decisão tomada por Drogo: a de permanecer no forte, julgando que existam razões para ali ficar e se estabelecer, por mais que elas sejam desconhecidas. No terceiro trecho, por meio do discurso indireto livre, o narrador traduz os pensamentos de Drogo em estado de quietude em que, mais uma vez, temos explicitada de forma cabal a inércia da personagem.

Bakhtin (2014), em seu célebre estudo sobre a questão do cronotopo, dirá que é impossível separar tempo e espaço. Ora, se notarmos, o romance de Buzzati, apesar de lidar com o tempo, precisa ancorar-se no espaço da fortaleza para alcançar suas possibilidades. Assim, nesse tocante, podemos afirmar que o narrador funde os dois elementos, criando, com isso, uma espécie de alegoria na realidade:

[...] Passarão alguns dias antes que Drogo entenda o que aconteceu. Será então como um despertar. Olhará à sua volta, incrédulo; depois ouvirá um barulho de passos vindo de trás, verá as pessoas, despertadas antes dele, que correm afoitas e o ultrapassam para chegar primeiro. Ouvirá a batida do tempo escandir avidamente a vida. [...] E se perguntar quanto falta do caminho, ainda lhe apontarão o horizonte, mas sem nenhuma bondade ou alegria. [...] Até Drogo ficar completamente sozinho e no horizonte surgir a estria de um imensurável mar parado, cor de chumbo. Então já estará cansado, as casas, ao longo da rua, terão quase todas as janelas fechadas, e as raras pessoas visíveis lhe responderão com um gesto desolador: o que era bom ficou para trás, muito para trás, e ele passou adiante, sem dar por isso. [...] São as últimas vezes que chegarão até ele, na noite, as suaves imagens de um mundo completamente feliz." (BUZZATI, 2017, p. 39-40).

No fragmento, o narrador imprime a ação do tempo sobre as coisas que direta ou indiretamente permeiam a vida de Giovanni Drogo. Essas coisas tornam-se simbólicas, meramente coisas, sem a possibilidade da formação de signos que lhe reative sentimentos de felicidade. Em determinado ponto, o tempo terá modificado tudo, mesmo o espaço, o que afetará a vontade de inerte do protagonista em querer mudar. Os olhares recairão sobre Drogo em tom de mofa - é isso que se deixa escapar nas projeções feitas pela voz que narra. É neste momento que o narrador atinge um grau exacerbado de ampliação do afeto de angústia, anunciado desde seu primeiro pronunciamento. $\mathrm{O}$ fato de Drogo passar a narrativa toda sem 
conseguir desvencilhar-se do forte implica que a sua vida acaba por coisificar-se. O tempo se perde no espaço, os dois tornam-se um. Em um outro momento da narrativa, temos:

Não teve a mais remota dúvida de que aquela noite seria muito triste para ele, que naqueles degraus, exatamente naquela hora, estaria terminando sua juventude, que no dia seguinte, por nenhuma razão especial, não voltaria mais ao velho sistema, nem mesmo no outro dia, nem mais tarde, nem nunca (BUZZATI, 2017, p. 163).

No trecho, que sucede-se em grande distância do anterior, o discurso delineia a degradação do corpo tanto pelo tempo quanto pelo espaço, promovendo uma amplitude breve, mas cujo alcance conserva a proximidade entre o momento de evocação e a ação evocada. Ou seja, um Drogo maduro reconhece que não impetra mais permanecer vivo, assim como, depois de anos passados, não conseguiu permanecer no Forte. Já não há mais espaço seguro, a proteger, nem mesmo inimigo. A esperança, que no romance todo se deu pela espera dos Tártaros, se desvanece por completo. Lutar com a morte, apresar de ser "a mais nobre das batalhas" (CANDIDO, 1990, p. 65), é uma luta vã.

\section{Considerações Finais}

Ao buscarmos discutir a categoria de tempo por meio da análise das anacronias de antecipação, ou prolepses, presentes no romance $O$ Deserto dos Tártaros, de Dino Buzzati, constatamos, para além do estudo essencialmente vital desse fenômeno - que se deu tanto pela observação da imanência do texto como na investigação do discurso, o que nos permitiu acessar o tipo de relação estabelecida entre tempo e personagem - a ideia de vida está, eminentemente, atrelada à de passagem temporal. Ou seja, é pela experiência adquirida via temporalidade que o sujeito pode - ou não - encontrar sua função na vida ou, dito de forma mais filosófica, sua condição existencial.

Acreditamos ter destacado na narrativa que a categoria tempo é o elemento por meio do qual as personagens são construídas e dimensionadas na história. A temporalidade é a responsável não apenas pela arquitetura dos actantes, como também é a esfera que delibera as ações e que move o enredo, muito embora, apesar de haver estruturas verbais, sintamos a estagnação do tempo porque há o viés da espera, respaldado pelo sentimento heroico infundido nas personagens.

A relação entre Giovanni Drogo e o tempo demonstra que o emergir dos sentimentos de angústia se dão via projeção de espaços fechados, reclusos, distantes, capazes de acionar e desencadear conflitos internos. Isso confere ao romance certo pendor existencialista - questões universais sobre o existir são colocadas em xeque, o humano é revelado como um cativo do tempo, fadado a percorrer os caminhos tortuosos das escolhas constantes e essenciais.

Ora, tais passos apenas reiteram a conhecida afirmativa de Lucáks (2000) de que a imagem do herói é apenas efêmero, pois esse sujeito está fadado ao fracasso, em pleno processo de decadência. A expectação 
de Giovanni Drogo fez ruir suas ânsias, os quereres para uma vida frondosa e repleta de momentos de lassidão em detrimento do incerto, improvável, mas incitante. Há na espera um poder capaz de evitar o alcance do prazer indelével. Em outros termos, por vias existenciais, é preciso viver o tempo, por mais complexo que ele seja.

Destarte, podemos afirmar, em conclusão, que se o tempo é um problema filosófico de longa extensão, sua reflexão traz à tona não somente questões subjetivas, permeadas por escopos e possibilidades, mas também permite a abertura de um espaço de ponderações que consegue fazer com que nos encontremos melhor conosco e com nossas refregas existenciais.

\section{Referências}

BAKHTIN, Mikhail. Questões de literatura e de estética: A Teoria do Romance. Trad. Aurora Fornoni Bernardini et al. 7 ed. São Paulo: HUCITEC, 2014.

BUZZATI, Dino. O deserto dos Tártaros. Trad. Aurora Fornoni Bernardini e Homero Freitas de Andrade. $6^{a}$ ed. Rio de Janeiro: Nova Fronteira, 2017.

CANDIDO, Antonio Candido. As quatros esperas. Novos Estudos, São Paulo, n. 26, p. 49-76, 1990. Disponível em: http://novosestudos.com.br/. Acessado em 05 de nov. de 2020.

FIORIN, José Luiz. As astúcias da enunciação: as categorias de pessoa, espaço e tempo. São Paulo: Editora Ática, 1996.

LUKÁCS, Georg. A Teoria do Romance. Trad. José Marcos Mariani de Macedo. São Paulo: editora 34, 2000.

NUNES, Benedito. O tempo na narrativa. São Paulo: Edições Loyola, 2013.

REUTER, Yves. Introdução à análise do romance. Trad. Angela Bergamini. $2^{\mathrm{a}}$ ed. São Paulo: Martins Fontes, 2004.

SANTOS, L. A. B.; OLIVEIRA, S. P. Sujeito, tempo e espaço ficcionais - Introdução à Teoria da Literatura. São Paulo: Martins Fontes, 2001. 